\title{
Parliamentary Ethics Regulation and Trust in European Democracies
}

Nicole Bolleyer \& Valeria Smirnova

This paper presents a three-dimensional conceptualization of conflict of interest (COI) regulation directed towards assuring the impartial and unbiased decision-making of parliamentarians. We distinguish and separately measure (based on a new dataset) $\mathrm{COI}$ Strictness, Sanctions and Transparency and show they indeed constitute empirically separate dimensions of parliamentary ethics regimes adopted in European democracies. To illustrate the usefulness of our indices, we examine the relationship between them and trust in national parliaments across 25 democracies. Unlike our Sanction and Transparency Index, the COI Strictness Index (composed of strictness of rules and enforcement) has a significant and robust negative association with trust, which highlights the importance of disentangling different elements of $\mathrm{COI}$ regimes. While future research has to explore the causal relationships between $\mathrm{COI}$ regulation and trust, capturing the complexity of $\mathrm{COI}$ regimes in an unbiased fashion and thereby making them comparable across European democracies is an essential step towards doing so.

Forthcoming: West European Politics 2017

Keywords: Conflict of interest regulation, parliamentary ethics, rule strictness, enforcement, disclosure, transparency, cross-national measurements 


\section{The Importance of Parliamentary Ethics Regulation}

Institutional accountability mechanisms in representative democracies ought to ensure that central democratic agents such as elected representatives act in line with citizens' interests. They are essential to sustain democratic legitimacy (Olsen 2013). Yet to analyse their consequences requires us to conceptualize and measure them (Bovens 2010: 960-1). This paper does so with a focus on a group of accountability mechanisms whose usage has expanded considerably over the last years: the regulation of conflict of interest (COI) which encompasses the range of formal-legal requirements or restrictions ${ }^{1}$ to assure publicly elected officials' impartial or unbiased decision-making (Allen 2008a: 307-8; Nikolov 2013: 407; Demmke and Henökl 2007). More concretely, we ask how conflicts of interest that national parliamentarians might encounter are regulated in European democracies. How can we systematically capture differences in COI regulation suitable for large-scale crossnational analysis to assess how they matter?

To assess the nature of ethics regimes regulating parliamentarians in his or her activities as public representative ${ }^{2}$ is important as self-regulation - traditionally the norm in the field of parliamentary ethics - is increasingly considered insufficient. Both the autonomy of parliamentarians as individual office-holders as well as of parliaments as collective institutions to generate their own solutions to conflict of interest problems has generally decreased over the last decades, often in response to scandals or other crises (Atkinson and Mancuso 1991: 475; Williams 2006; Allen 2008a). The enhanced saliency of parliamentary ethics as regulatory 'target area' has become visible through new forms of transparency requirements, registers or the establishment of new 'ethics bureaucracies' that enforce such regulations. These developments not only highlight a growing complexity of parliamentarians' regulatory environments as such. They point to a particular suspicion

\footnotetext{
${ }^{1}$ Our analysis excludes voluntary rules which are not formally enforceable (Sieberer et al 2016: 63).

${ }^{2}$ This is distinct from anti-corruption or anti-bribery legislation regulating MPs as self-interested individuals who try to gain financial benefits. Giving in to conflicts of interest in legislative decision-making is associated with bias but does not necessarily generate private financial gain.
} 
towards elected office-holders who (at least partly) regulate themselves, including sensitive areas such as the setting of their MP salaries or defining the rules of access to and usage of expenses, parliamentary grants or funding for political parties (e.g. Demmke and Henökl 2007: 35; Clark 2015: 2; see also Biezen and Kopecký 2008; Allen 2011; Casal Bértoa et al 2014; Allen and Birch 2015).

$\mathrm{COI}$ regulation fundamentally refers to MPs' exercise of their representative function as it aims at either preventing or disclosing those situations in which parliamentarians' impartial and objective exercise of professional duties might be compromised (Messick 2014: 114115; Nikolov 2013: 412). Consequently, unlike earlier cross-national studies focused on the regulation of financial asset disclosure (e.g. Djankov et al 2010; Krambia-Kapardis 2013; van Aaken and Voigt 2011), we propose a more encompassing concept as suggested in comparative law covering 'preventing mechanisms' (e.g. bans) and 'disclosure mechanisms' (e.g. transparency requirements) (Rose-Ackerman 2014: 14; Mattarella 2014: 33-4), capturing the full range of constraints imposed on parliamentarians. More specifically, this paper conceptualizes a continuum of constraints as foundation for measuring different components of 'COI regulatory regimes' (Allen 2008b: 56-7): the strictness of the rules adopted, the presence and strength of enforcement structures, sanctions against rule violations and transparency requirements. While doing justice to the growing empirical diversity of COI structures (e.g. Demmke et al 2007), considering disclosing and preventive mechanisms as alternative means to counter unethical behaviour in legislative processes overcomes the methodological problem of functional equivalence, a challenge in comparative politics research more broadly (van Deth 1998). It recognizes that making positions or behaviour incompatible with public roles pre-empts the need for disclosure. Studying disclosure regulation in isolation risks categorizing 'most different' regulatory environments jointly as 'weakly regulated' or 'permissive', overlooking that disclosure regulation might be weak because democracies have adopted little COI regulation or because they heavily rely on bans instead. 
The study of $\mathrm{COI}$ regulation is of broader theoretical and empirical significance as it intersects with several on-going debates cross-cutting public policy, comparative politics and political theory. Conceptualizing and measuring multiple dimensions of $\mathrm{COI}$ regulation links important theoretical work on different public accountability mechanisms with empirical research on the changing nature and growing complexity of parliamentary ethics regulation (Demmke et al 2007; Bovens 2010; Olsen 2013). Importantly, it addresses calls for the development of conceptually sound, wide-ranging, comparative, and well-constructed indices of central mechanisms directed towards ensuring the 'political integrity' of public office-holders (Rose and Heywood 2013: 157; Rose-Ackerman 2014). We deliver such indices by systematically integrating - both conceptually and empirically - elements of COI regulation usually studied in isolation (Djankov et al. 2010, Krambia-Kapardis 2013, Nikolov 2013; van Aaken and Voigt 2011), which has been highlighted as problematic by theoretical works, asking for the study of combinations of distinct measures (e.g. sanctions, the nature of enforcement structures) central to a more nuanced understanding of how accountability arrangements operate (Olsen 2013: 450). Furthermore, our analysis contributes to discussions about the consequences of adopting distinct types of mechanisms, such as transparency measures' implications for citizens' trust (O'Neill 2002), how distinct accountability mechanisms compare to each other in this respect (Bovens et al 2014), and about the consequences of regulation generally (economic or political) on citizens' attitudes and beliefs (Aghion et al. 2010).

In the following, we conceptualize and then measure $\mathrm{COI}$ regulation drawing on a new dataset covering 26 European democracies. We show that - in line with our conceptualizations - $\mathrm{COI}$ regimes vary along three empirical dimensions and discuss the cross-national patterns found. Then, we illustrate the usefulness of distinguishing different dimensions of $\mathrm{COI}$ regimes by examining how our indices associate with trust in national parliaments. Different from COI Sanctions and COI Transparency, our COI Strictness Index 
shows a significant and robust negative association with individual level trust in national parliaments. This stresses the importance of disentangling different elements of $\mathrm{COI}$ regulation when trying to explore how such regulation relates to other variables, be they attitudinal or behavioural. We conclude with a discussion how the concept and measures presented can be made useful in other areas of comparative research.

\section{Conceptualizing Conflict of Interest Regulation}

COI regulation understood as ethics regulation directed against representative bias encompasses legal mechanisms directed towards either preventing situations (e.g. through bans and incompatibility rules) or disclosing situations (e.g. through transparency requirements) where public officials' impartial and objective exercise of professional duties might be compromised (Messick 2014: 114-115). This distinction between bans/limits and disclosure mechanisms is useful analytically since it allows us to systematically map out configurations of mechanisms according to the constraints they impose on the office-holders concerned across the core substantive areas of $\mathrm{COI}$ regulation (e.g. the receipt of gifts or the holding of ancillary posts). Disclosing constraints are less intrusive than preventive mechanisms, since MPs are not prevented from engaging in any behaviour. Distinguishing these mechanisms allows us to consider the compensatory nature between them, namely that preventive mechanisms that restrict politicians in what they can legally do (e.g. through incompatibilities rules or bans) decrease the need for disclosure requirements in the area concerned, essential to arrive at unbiased cross-national measures of $\mathrm{COI}$ regulation.

\section{Three Elements of COI Regimes: COI Strictness, Sanctions, Transparency}

When distinguishing preventive from disclosing $\mathrm{COI}$ mechanisms we refer to the constraining nature of $\mathrm{COI}$ rules. However, the type of rules adopted is only one aspect of the 'COI regime' overall, which encompasses also the infrastructure or instruments created or available for rule implementation (Allen 2008b: 56-7). We therefore distinguish three basic elements of the $\mathrm{COI}$ regime reflecting distinct ways of constraining the behaviour of the 
office-holder they apply to: 'COI Strictness' captures aspects in the regime that increase the likelihood that formal COI violations are officially detected and notified (the strictness of rules and the nature of enforcement); 'COI Sanctions' captures the costs imposed on parliamentarians when COI violations are detected and 'COI Transparency' captures the conditions for third party control. Figure 1 displays the analytical relationships of these three elements to the basic concept of 'COI regime' and to the analytical distinction between preventive and disclosing mechanisms used to characterize the constraints inherent in each of the elements.

Figure 1: Core Elements Underpinning COI Regimes

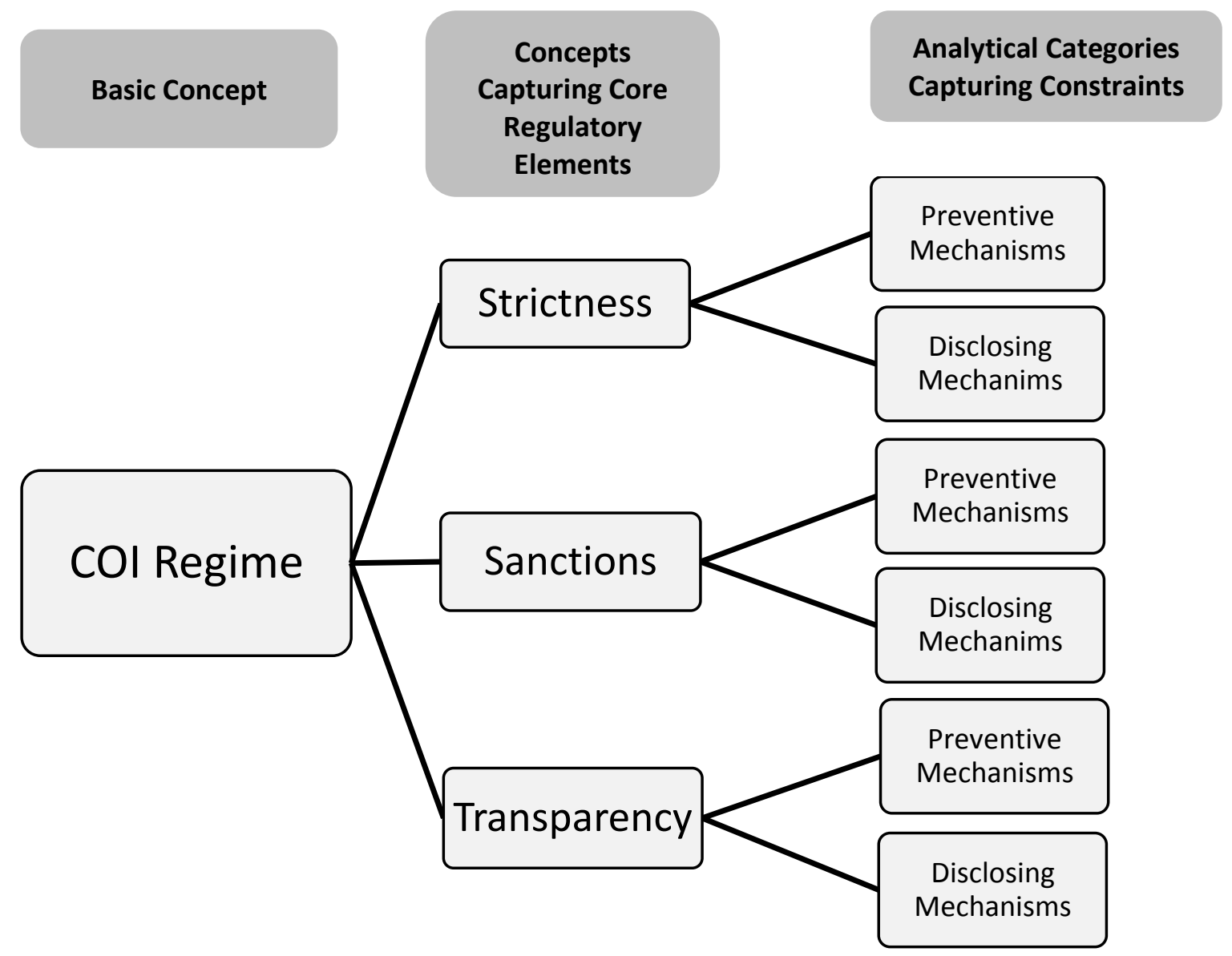

Among the three elements, COI Strictness is theoretically most central. The presence and strictness of rules determines the overall scope of incentives directly structuring the behavior of MPs as representatives and law-makers. Strictness logically constitutes a necessary 
condition for both transparency measures and sanctions. Information about parliamentarians can only be made public, if it had to be officially reported in the first place. Only if we find COI rules, sanctions can be in place to punish their violation. Finally, rule specificity and the strength of enforcement affect how meaningful and effective both sanctions and transparency measures can be. Rules define which information ought to be made transparent, while separate enforcement structures create an important foundation for sanction mechanisms can be applied.

Moving to the specification of each element and starting with COI strictness, from the perspective of parliamentarians, the presence and (if adopted) nature of COI rules can be conceptualized as constraints that make it more likely that officially recognized rule violations are detected. By definition, if conflicts of interest remain unregulated, parliamentarians cannot violate any rules. Vice versa, the higher the number of areas in which $\mathrm{COI}$ rules are adopted (e.g. regulation of gifts, accessory posts, assets), the stricter and more clear-cut and less ambiguous these rules are (e.g. through the complete ban of certain behaviours), the more likely rule violations become. If, in addition, any observable violations are investigated and confirmed by an actor formally in charge of doing so (Allen 2011: 213; Rosenthal 2005: 158; see also Gay 2006), the officially recognised violation of COI regulation as a form of misconduct is most likely. Consequently, conceptually, we need to consider rule strictness and enforcement in conjunction with each other.

A strong enforcement structure for the implementation of regulation is usually associated with the capacity to sanction rule violations (e.g. Nassmacher 2003; O'Halloran 2011; Mattarella 2014). Yet there are two reasons to treat the 'range of sanctions underpinning $\mathrm{COI}$ rules' as a separate element of the COI regime. First, conceptually speaking, COI strictness and $\mathrm{COI}$ sanctions impose different types of constraints on the public officeholders whose behaviour they aim at influencing. While strict rules combined with strong enforcement structures make it less likely that parliamentarians can hope for violations not to 
be officially detected, sanctions shape the relative costs of rule violations once they are detected. Second, empirically speaking, the assumed link between COI sanctions and enforcement structures is only partial: not all sanctions attached to violations of $\mathrm{COI}$ regulations are attached to or controlled by enforcement structures established for dealing with $\mathrm{COI}$ issue. In fact, we might have a $\mathrm{COI}$ regime that does not contain any enforcement structures in charge of $\mathrm{COI}$ regulation. Still, a considerable range of $\mathrm{COI}$ violations could be answered by criminal sanctions controlled by courts. Focusing on sanctions as controlled by enforcement structures in charge of COI monitoring (rather than on the full range of sanctions underpinning $\mathrm{COI}$ rules) would lead to misleading comparative evaluations of $\mathrm{COI}$ regimes' properties.

Public transparency requirements (rather than mere intra-institutional disclosure) assuring easy public access to a wide range of information about parliamentarians (usually via online release) can provide the basis for 'third party control' by the media, interested organizations or individual citizens (Djankov et al 2010). They are sometimes considered as a possible substitute for a strong institutional enforcement structure or as a complement to the latter (Nassmacher 2003: 10-12). However, for conceptual reasons, we treat transparency measures separate from $\mathrm{COI}$ strictness (of which enforcement forms part). The mere release of information on MPs' activities to the public might allow for third party control but does not necessarily contribute to the capacity of the $\mathrm{COI}$ regime to detect officially recognized noncompliance with $\mathrm{COI}$ rules, the theoretical underpinning of $\mathrm{COI}$ strictness. Problematic practices might be occasionally picked up by the media and thereby generate reputational costs for the individual MP concerned (Krambia-Karpadis 2013: 46). However, accountability deficits can occur if the actors who are institutionally in charge to call others to accounts which might lack motivation, time and energy, knowledge or capabilities, a challenge particularly pronounced in the case of transparency measures where citizens play this role (Olsen 2013: 545; 556). Furthermore, 'control activity' of third parties or the media is bound to be much more time contingent (depending on the saliency of the issue area regulated), 
and thus not equivalent to the on-going monitoring of rule compliance by a public body in charge of detecting formal misconduct (Allen 2011:213).

\section{Constructing Indices of COI Regulation}

To examine whether our three-dimensional conceptualization of $\mathrm{COI}$ regimes matches regulatory patterns across European democracies (i.e. whether they can indeed be systematized along three empirical dimensions) we compiled a new dataset. We coded COI regulation (covering both preventing and disclosing mechanisms) based on the evaluation reports from the $4^{\text {th }}$ Greco round on "Corruption prevention in respect of members of Parliament, judges and prosecutors", which provided the most encompassing and standardized information on COI regimes adopted in a wide range of EU democracies (see Online Appendix A for details on alternative sources and the coding process). Among those democracies evaluated by $\mathrm{Greco}^{3}$, we restricted our sample to fully consolidated European countries to assure basic unit homogeneity in terms of democratization, the centrality of parliamentary institutions, rule of law and of the basic administrative capacity to implement the studied regulation. This left us with a sample of 26 countries.

\section{Three Elements of COI Regimes - Three Empirical Dimensions?}

In a first step, we constructed four basic components that we expect to underpin three dimensions COI strictness (composed of rule strictness and enforcement), COI sanctions and COI transparency. For each, we made use of rankings and a linear aggregation method. This choice is important as we are interested in capturing the constraints inherent in the COI regime across several dimensions with various predictors on an ordinal scale. As most composite indicators (OECD 2008: 31) all our indices are constructed on the basis of equal weights, in line with our analytical set-up emphasizing equal importance of $\mathrm{COI}$ indicators

\footnotetext{
${ }^{3}$ Greco is the "Group of States Against Corruption", an international organisation that was established in 1999 by the Council of Europe to monitor States' compliance with the organisation's anti-corruption standards.
} 
capturing different constraints inherent in COI regimes (see Figure 1 above). The final scores for each index are standardized from zero to one.

To operationalize our analytical framework, we assess rule strictness by capturing the type of legal mechanism employed and rank the respective regulatory configurations according to the constraints they imply across 11 core areas of $\mathrm{COI}$ regulation. In line with earlier studies, those areas are: public and private accessory activities, assets, contracts with state authorities, employment offers (or cooling off regulations), income, liabilities, third party contacts, gifts, use of confidential information, handling of conflicts of interest in legislative decision-making $^{4}$ (see Djankov 2010; Nikolov 2013; Mattarella 2014). The distinction between preventive and disclosure mechanisms allows us to identify five rule configurations with regard to each of the areas that range from the absence of constraints to complete prohibition, which we assign scores from "zero" to "four" respectively (see Table 1). This coding approach assures an unbiased categorization of the legal mechanisms used across $\mathrm{COI}$ regimes in terms of constraints they impose on MPs and avoids counting requirements to disclose information as equally constraining as rules that prohibit or restrict actual behavior. The scores for each of the 11 substantive areas of COI regulation are standardized from 0 to 1 and averaged to an overall country score capturing the cOI regime's rule strictness. ${ }^{5}$

Table 1: Combinations of Legal Mechanisms and Rule Strictness Scores ${ }^{6}$

\begin{tabular}{|c|c|c|c|c|c|}
\hline Prevention on COI & No rules & No rules & Restrictions & Restrictions & Total ban \\
\hline Disclosure of COI & No rules & Disclosure & No rules & Disclosure & - \\
\hline $\begin{array}{c}\text { Overall COI } \\
\text { strictness score }\end{array}$ & 0 & 1 & 2 & 3 & 4 \\
\hline
\end{tabular}

Note: The darker the coloring, the higher the level of constraint in the combination of mechanisms.

\footnotetext{
${ }^{4}$ This contains two categories of regulation: those that obligate MPs to declare regarding individual decisions that they are affected by a conflict of interest or provisions that require MPs to excuse themselves.

${ }^{5}$ Figure $A 1$ in Online Appendix A shows the distribution of the rule strictness scores reflecting the combinations of legal mechanisms country by country.

${ }^{6}$ See Online Appendix B which illustrates this logic with reference to the example of the regulation of gifts.
} 
To capture the constraints inherent in the enforcement structures we assess whether we find monitoring bodies or units to underpin preventive rules and disclosure rules respectively. If present, we assess the nature of these bodies (or body - some countries use the same body for both types of $\mathrm{COI}$ rules, others use separate ones) using two criteria, reflecting our theoretical discussion of properties that make it more likely that such a body actively fulfills its monitoring function in terms of motivation and capacity. Regarding the motivation to monitor, we consider whether enforcement bodies are independent from parliament and not affiliated with any political party (Nassmacher 2003: 13; Clark 2015: 2). ${ }^{7}$ For instance, in France we find an independent body responsible for implementing disclosing rules: the Supreme Authority for the Transparency of Public Life ${ }^{8}$, while preventive mechanisms are monitored by the National Assembly's Commissioner for Ethical Standards, which is a part of the French parliament, thus, does not qualify as independent. Finland lacks any specific monitoring structures to implement disclosure rules, but speaker and committee chairs in parliament are responsible for monitoring compliance with preventive mechanisms, which again does not qualify as independent. Additionally, we account for a body's monitoring capacity which is considered as broad if the body can examine the correctness of information provided by parliamentarians in relation to their compliance with preventive or disclosing $\mathrm{COI}$ rules. If that is not the case we consider its monitoring capacity as narrow. ${ }^{9}$ Countries are ranked from all-permissive regimes with no specific body for $\mathrm{COI}$ enforcement in place for either preventive or disclosing rules to most constraining enforcement regimes with independent watchdogs with broad monitoring capacity for both types of rules. ${ }^{10}$ The final scores are standardized from zero to one.

\footnotetext{
${ }^{7}$ See Figure B3 in Online Appendix B for an overview of the scores capturing enforcement in our sample.

${ }^{8}$ The Supreme Authority for the Transparency of Public Life is coded as an independent body as it consists of six appointees from the high courts of the state (Conseil d'État, Court of Cassation and Court of Audit), two parliamentary appointees and one appointee of the President of the French Republic.

${ }^{9}$ We assign a score "zero" on one end of the spectrum to the all-permissive regimes and a score "eight" to the most constraining ones. A regime without an enforcement structure for preventive COI rules but an independent watchdog with broad monitoring powers for disclosing rules takes an intermediate position with a score of "four".

${ }^{10}$ In comparison to the measurement of COI regime's rule strictness, we capture the constraints inherent in $\mathrm{COI}$ enforcement structure overall (i.e. we do not weigh enforcement of preventive rules more heavily than
} 
Both rule strictness and strength of enforcement contribute to the likelihood that formal $\mathrm{COI}$ rule violations are officially detected and notified, and hence belong together. Also empirically, the Spearman test confirms that the two measures highly and significantly correlate with each other $(\mathrm{N}=26, \rho=0.73, \mathrm{p}<.01)$. The coefficient is positive and very high, thus, the introduction of stricter COI rules is positively associated with the creation of stronger enforcement structures. Therefore, an index of COI Strictness should encompass both components. Figure 2 depicts a monotonic relationship, which underpins our conceptually driven decision to combine information on rule strictness and enforcement into one COI Strictness Index empirically. ${ }^{11}$

Figure 2: Relationship between COI Rule Strictness and Enforcement

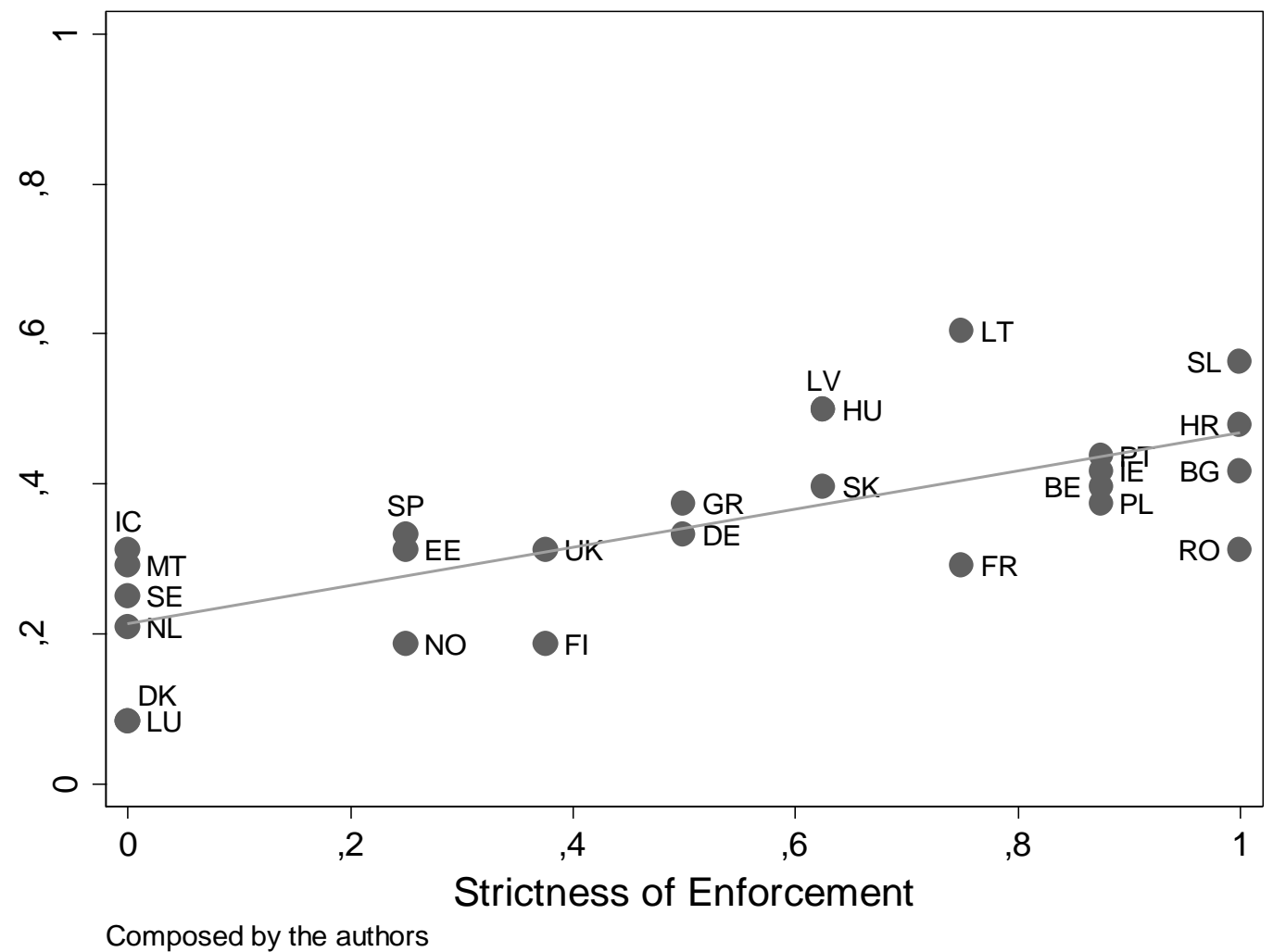

enforcement of disclosing rules) to assess whether any given rules are underpinning by enforcement structures and if so by which type.

${ }^{11}$ It may seem that combining rule strictness and enforcement without weighing can lead to the unwanted weighting of the components constituting these two parameters (OECD 2008: 31). Yet we avoid this problem as we systematically transfer our ratings assigned to these components into the proportions of constraints in the regulation.

See Figure B4 in Online Appendix for the distribution of the COI Strictness Index in the sample. 
Figure 2 also points to interesting cross-national variation, most notably that COI strictness tends to be higher in old democracies than new ones. While we find a number of old democracies that have adopted constraining $\mathrm{COI}$ regimes (Ireland, Belgium and France), most old democracies show below-average scores such as the Scandinavian countries. While we will return to this when discussing COI regimes as a means to reestablish trust in parliaments (trust that is notably lower in new democracies), it is noteworthy that we find similar patterns in other areas unrelated to parliamentary ethics such as party finance regulation (Casal Bértoa et al 2014: 359; 374-75) or party-specific regulations in constitutions (Biezen 2012: 201). This enhances confidence in our measures but also echoes classical arguments associating democracies with national regulatory styles that cross-cut distinct areas of regulation (Epstein 1989; Jepperson and Meyer 1991).

Following Casal Bértoa et al. (2014), we develop an ordinal scale for measuring the range of sanctions. This measure captures whether the violation of preventing and of disclosing rules in a given $\mathrm{COI}$ regime can be punished by criminal sanctions, by administrative sanctions or both. Criminal sanctions are treated as more constraining than non-criminal ones. ${ }^{12}$ Figure 3 shows considerable cross-country variation. Of 16 democracies with a sanction score above 0.5, only four are old democracies, with France and Belgium having maximum scores, echoing the earlier picture that new democracies have more constraining regulation.

\footnotetext{
${ }^{12}$ See further details on the rank assignment in Appendix C.
} 
Figure 3: Sanction Scores Underpinning COI Regimes

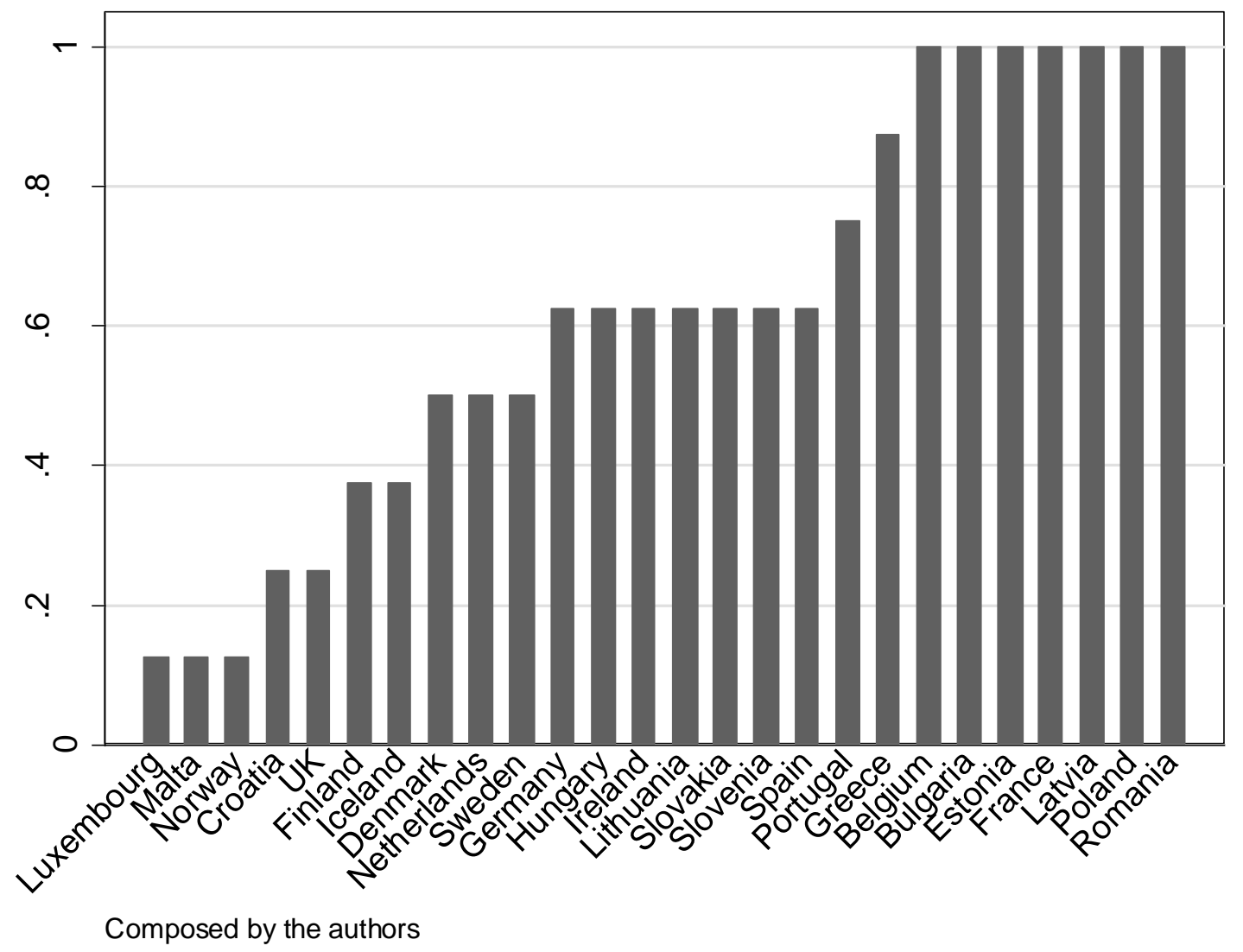

Our transparency index captures the possibility for third party control and differentiates between modes of access to information related to $\mathrm{COI}$ rule implementation. We use three criteria to assess conditions for third party access to information as related to the compliance with or violation of preventive and disclosure $\mathrm{COI}$ rules. We consider whether information is disclosed publically (whether no public access is possible, information is provided on request, or there is a free access via printed or online mass media); the scope (or completeness) of information that is made publicly available (whether the institutions that release information to the public present all or only part of the information they receive about the parliamentarian); and finally whether information about rule violations by MPs is released or not, a form of 'shaming through transparency'. ${ }^{13}$ Figure 4 shows the variation in our

\footnotetext{
${ }^{13}$ A COI regime has a transparency rank of "eleven" if all the transparency options are coded as present, which indicates the maximum possible level of transparency with regard to both preventive and disclosure rules and a "zero" if none are present. Rank "five" is assigned to regimes that, for instance, have transparency
} 
sample. ${ }^{14}$ Compared to the other two indices, transparency scores are more diverse, highlighting the importance to keep the three aspects separate. Indeed, old democracies being located at both ends of the spectrum: the UK and Bulgaria have adopted the most extensive, compulsory COI transparency measures with Denmark having no compulsory transparency measures at all.

Figure 4: Transparency Requirements Underpinning COI Regimes

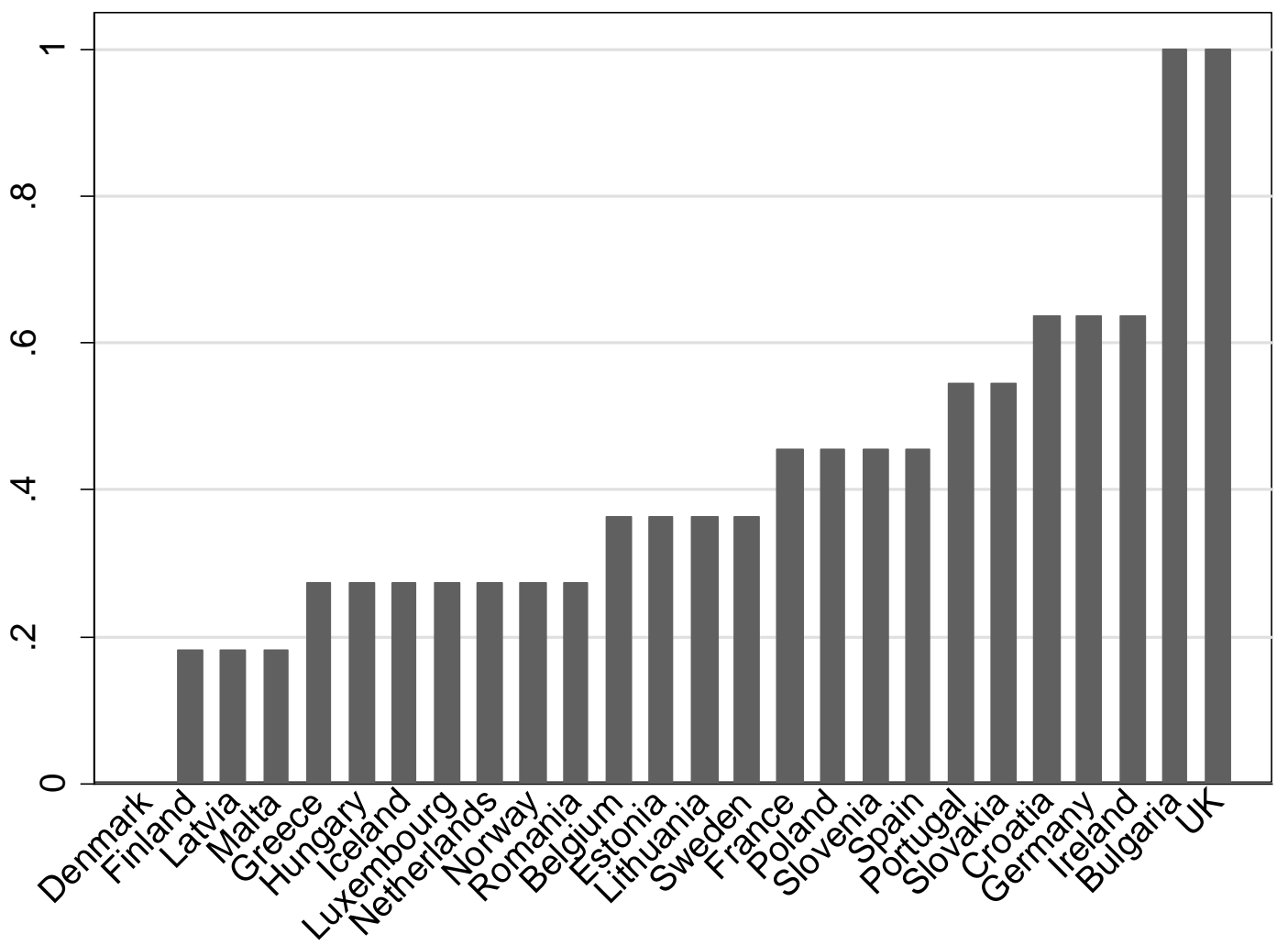

Composed by the authors

requirements in relation to both preventive and disclosing rules, yet in either case the scope of the information published is limited, while no information on rule violations is released. Note this is only one possible institutional constellation that might receive a rank "five".

${ }^{14}$ We construct an additive index of overall constraints implied by transparency requirements as linked to preventing and disclosing rules. We do not prioritize preventive rules over the disclosing rules in this case as there are no theoretical reasons or empirical indication that information release on non-compliance with one type of rule is perceived as more or less problematic by those regulated or by the public. Note that, as with the measure of rule strictness, the indicators are interdependent (e.g. if no public information release is required, the scope of such release is of no relevance). We consider the whole theoretically possible range of variation and also assure equal distances between the different levels of the index. 
So how are our sanction and transparency indices related to each other or and to our strictness index? Again in line with our theoretical expectations both the COI Sanction Index and the Transparency Index correlate with our COI Strictness Index by far less strongly ( $\rho=$ $0.54, p<.01$ and $\rho=0.54, p<.01$ respectively) than rule strictness and enforcement (see above). Our conceptual discussion has already pointed out that our three indices share some common variability. This is confirmed empirically: as correlations show COI strictness is a necessary but not a sufficient condition for adopting transparency requirements or sanctions. Simultaneously, the Spearman test between the COI Sanction Index and the COI Transparency Index is not significant indicating independence of these two indices from each other $(\rho=0.21, p>.29)$. This stresses the different rationales underpinning countries' adoption of sanctions and transparency requirements respectively and thus the need to treat COI Sanction Index and COI Transparency Index separately in empirical analyses. The empirical variability of combinations of different $\mathrm{COI}$ dimensions is illustrated by cases that prioritize individual dimensions such as in the case of the UK which has (with Bulgaria) the highest score on transparency but comparatively low scores on the two indices, particularly sanctions. Last but not least, the Cronbach's $\alpha$ for the three indices put together constitutes only 0.64 signifying a lack of coherence between the indices when they are pulled together and treated equally, and thus supporting our theoretical expectations.

\section{Why to Distinguish Different Elements of COI Regimes? COI Regulation and Trust in}

\section{National Parliaments - An Empirical Illustration}

Among policy-makers ethics regulation applied to parliamentarians is often discussed as a potential remedy against citizens' growing alienation and distrust in parliamentary institutions (OECD 2005: 16-18; NDI 1999: 3-4). Figure 5 shows that the high mean trust levels in national parliament in a democracy ${ }^{15}$ is associated with a low COI Strictness Index

\footnotetext{
${ }^{15}$ See for details on the trust data the next section and Appendix D. Note Norway could not be included as the country was not covered in the Eurobarometer data used.
} 
(Pearson's $r=-0.76, p<0.01, n=25)$. Countries such as Denmark, Sweden, Finland, Luxembourg and Malta are particularly high on trust and low on COI Strictness, while Slovenia, Bulgaria and Lithuania show opposite patterns, with countries such as Germany, UK and Spain located in the middle.

Figure 5: Trust in National Parliament and COI Strictness

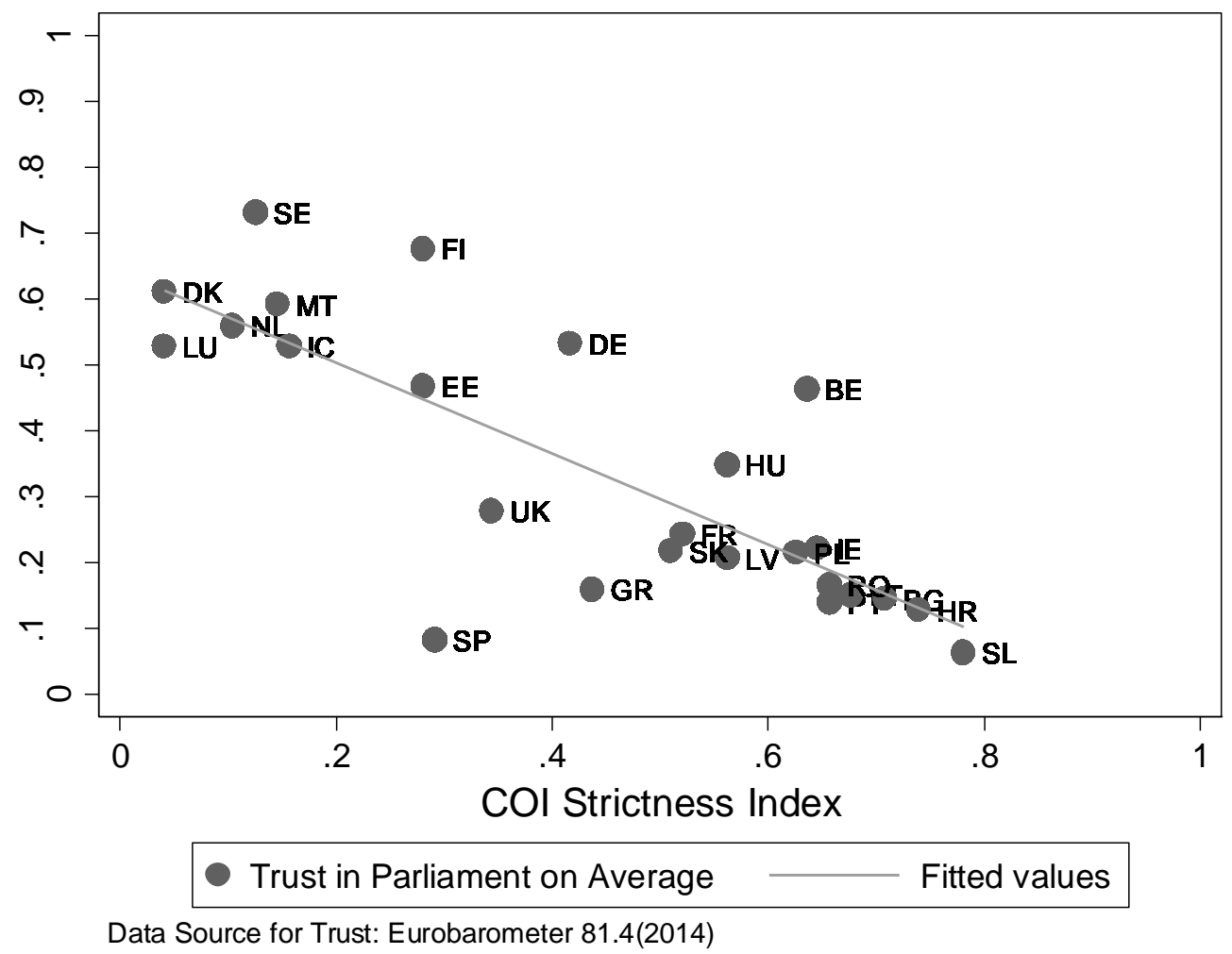

A number of scholars have been critical of the idea, wide-spread among practitioners, that stricter regulatory constraints could re-establish trust in those public officials no longer considered trustworthy. While we do not aim to test the nature of the relationship between $\mathrm{COI}$ regulation and trust as such, these arguments provide a theoretical rationale for engaging in an examination which aims at empirically demonstrating the usefulness of distinguishing different elements of the COI regime as proposed in our analytical framework.

So what are the arguments in favour of a negative relationship between COI regulation and trust? For once, to make parliamentarians subject to a strict $\mathrm{COI}$ regime might convince 
citizens that parliamentarians' won't get away with unethical behaviour as easily. Yet if "calling someone trustworthy means that the person can be trusted with a wide variety of unspecified activities" (van Aaken and Voigt 2011: 307, italics added to original), the presence of effective controls is different from making parliamentarians more trustworthy. Instead COI rule might 'institutionalize distrust' and make 'blind trust' less necessary as the law coerces MPs to behave ethically instead of relying on internalized norms of behaviour (van Aaken and Voigt 2011: 307), as "where we have guarantees or proofs, we don't need to trust. Trust is redundant" (O'Neil 2002a).

This points to two possible side-effects of stricter $\mathrm{COI}$ regulation: first, expanding citizens' information on parliamentarians' unethical behaviour is more likely to decrease trust in parliamentarians or parliament as institution, and stricter $\mathrm{COI}$ regulation does just that (Wilcox 2001: 10; see also Rosenthal 2005: 175; Ginsberg and Shefter 1994: 7; Loewenstein et al 2011), a potential dynamic that is amply highlighted in debates on the consequences of transparency measures in public life generally (O'Neil 2002b). COI regulation - as ethics regimes generally - is preventive. It aims at creating norms through which 'proper conduct can become second nature' (NDI 1999: 3). Thus, strict COI regulation is likely to foster trust only once parliamentarians' comply and no rule violations occur. If - at least initially - tougher regulation sheds light on more rule violations (intentional as well as unintentional ones) rather than preventing them, to have proof about wide-spread unethical behaviour might make matters worse than distrust predominantly fostered by rumours and suspicions or revelation about individual cases (van Aaken and Voigt 2011: 307). Consequently, intense monitoring can weaken or undermine trust (Olsen 2013: 454). Second, COI regulation itself might - unintentionally - raise citizens' expectations about what behaviour is acceptable and what is not, as ethics rules ought to be increasingly detailed to minimize misunderstandings (NDI 1999: 6). Specifying the formerly rather blurred boundary between what is acceptable and what not, $\mathrm{COI}$ regulation itself can become a 
catalyst enhancing public concerns about ethics (Rosenthal 2005: 175) and thereby raise the bar of what ethics regulation ought to achieve (Saint-Martin 2008: 48).

\section{Data and Operationalization of Variables}

To explore the relationship between our $\mathrm{COI}$ indices and trust, we make use of Eurobarometer 81.4 (2014) which measures trust in national parliaments, covering 25 of 26 countries in our sample. ${ }^{16}$ Trust is measured with the question whether a respondent tends to trust (1) or tends not to trust (0) national parliament. In all countries the survey was conducted after all elements of the COI regime captured by our indices were already in place. We include a range of individual control variables, in line with earlier studies on trust in national parliaments and public institutions more generally (e.g. Catterberg and Moreno 2005: 42; van der Meer 2010; van Aaken and Voigt 2011: 312-13; Zwerli and Newton 2011; Torcal 2014). Zwerli and Newton (2011: 73) argue that citizens trust political institutions more if they consider themselves as winners, socially or politically. We therefore control for individuals' perceived self-placement in society capturing their perceived status in society (and the political regime broadly conceived). The same goes for life satisfaction and for older and married respondents. In contrast, personal economic stability and perceived personal security should show a negative relationship. The former is measured as difficulties in paying bills ranging from frequent to seldom, the latter by expectations regarding one's personal employment situation, and as feeling safe in one's neighborhood. Psychological approaches, in turn, stress the role of personal interests - in our case in politics (Catterberg and Moreno 2005: 42). As our dependent variable is linked to the national level (individual trust in national parliament), we use an item capturing the self-perceived frequency of discussions regarding national political matters (ranging from low to high). Importantly, we control for trust in political parties which can be expected to 'colour' perceptions of trust in national political institutions composed of party politicians and control for the years of democratic

\footnotetext{
${ }^{16}$ We lost Norway because Eurobarometer (EB) does not include information on it.
} 
development. The longer a democracy is established the more likely citizens have experienced changes in political leadership and been on the 'winning side'. Furthermore, experiencing government alternation, citizens can be expected to gain trust in central democratic institutions such as parliament. Both rationales suggest a positive correlation. Finally, we coded a new macro variable 'political instability' which we expect to affect trust in parliament negatively. This dummy variable captures whether a country suffered from a destabilizing political event in the legislative term in which trust in parliament (our dependent variable) was measured or in the term prior or not (For more details on data and measurements see the Online Appendix D).

\section{Model Choice and Empirical Findings}

The analysis of the interclass correlation suggests we observe approximately a quarter of the variance in our dependent variable on the macro level as compared to the micro level $(I C C=0.24)$. We therefore fit a set of multilevel logistic regression models with a random intercept, as the Eurobarometer data measures trust to parliament in a binary fashion. Table 2 presents our results. ${ }^{17}$ Model 1 contains only control variables. Model 2 tests all the three indices against each other. Model 3 and 4 demonstrate effects of macrolevel controls in relation to our COI Strictness Index (the only index significant in Model 2). ${ }^{18}$ Model 5 shows the effect of the COI Strictness Index separately.

Table 2 shows that our COI Strictness Index shows robust and significant effects (Models 2$5)^{19}$. Hence, the more constraints the COI regime imposes in terms of rule strictness and enforcement (covering both preventive and disclosing rules), the lower the log-odds, and hence the lower the probability that citizens tend to trust national parliament, holding all other

\footnotetext{
${ }^{17}$ Note that tests for multicollinearity of the presented models do not reveal any problems.

${ }^{18}$ We are aware that 25 countries can be a critical sample size for a multi-level design. Note that the results of logistic regression with clustered standard errors are the same.

${ }^{19}$ Appendix $D$ provides details on additional robustness checks and tests regarding endogeneity and reverse causation.
} 
parameters constant. Our COI Transparency Index has a negative association to trust. The COI Sanction Index correlates with trust positively. While neither of the latter two indices shows robust significant results (see Model 2), the COI Transparency Index outperforms the COI Sanction Index when treated alone..$^{20}$ Thus, COI Sanctions have the least impact when comparing the three $\mathrm{COI}$ dimensions $(\mathrm{t}=0.06)$.

These findings hold despite our control variables having the theoretically expected significant effects. The measure of years of democracy is positively associated with trust in national parliament but only significant as long as we don't include our COI Strictness Index (Model 4). This might reflect a tendency in new democracies to impose stricter and more extensive $\mathrm{COI}$ regimes in comparison to the old democracies (Figure 2), which is in line with previous findings (Biezen and Kopecký 2008; Biezen 2012; Casal Bértoa et al. 2014). A higher selfplacement in society, overall life satisfaction, better employment expectations, higher personal economic stability, a safe neighborhood, and marriage status taken as indicators associated with the "winner status" of citizens are positively associated with a probability to trust in national parliament (Dunn 2012; Zmerli and Newton 2011). High levels of political knowledge also significantly increase the log-odds of tending to trust national parliament. A very important predictor of trust in parliament is trust in political parties as adding this control significantly improves the fit of the model (BIC falls by more than 20 percent). That said, having this variable excluded does not affect the performance of our indices (see Appendix D, Table D1). Finally, our findings hold when entering our political instability dummy (Model 3), despite the latter - as theoretically expected - showing a significant and robust negative effect on tendencies to trust in parliament.

\footnotetext{
${ }^{20}$ Appendix D Table D2 provides results for additional specifications.
} 
Table 2: Results of Multilevel Logistic Regressions with Random Intercept on Trust in National Parliaments

\begin{tabular}{|c|c|c|c|c|c|}
\hline DV: Trust in parliament & (1) & (2) & (3) & (4) & (5) \\
\hline \multicolumn{6}{|l|}{ Controls } \\
\hline \multirow[t]{2}{*}{$\overline{\text { Age }}$} & $0.003^{* *}$ & $0.003^{* *}$ & $0.003^{* *}$ & $0.003^{* *}$ & $0.003^{* *}$ \\
\hline & $(0.001)$ & $(0.001)$ & $(0.001)$ & $(0.001)$ & $(0.001)$ \\
\hline \multirow[t]{2}{*}{ Family status: married } & $0.159^{\star * *}$ & $0.159^{\star \star \star}$ & $0.159^{* \star \star}$ & $0.159^{\star \star \star}$ & $0.159^{\star * *}$ \\
\hline & $(0.041)$ & $(0.041)$ & $(0.041)$ & $(0.041)$ & $(0.041)$ \\
\hline \multirow[t]{2}{*}{ Life satisfaction } & $0.485^{\star \star *}$ & $0.488^{\star * \star}$ & $0.487^{\star * \star}$ & $0.487^{\star \star \star}$ & $0.487^{\star \star \star}$ \\
\hline & $(0.062)$ & $(0.062)$ & $(0.062)$ & $(0.062)$ & $(0.062)$ \\
\hline \multirow[t]{2}{*}{ Political knowledge } & $1.168^{\star \star *}$ & $0.167^{\star \star \star}$ & $0.167^{\star \star \star}$ & $0.167^{\star \star \star}$ & $0.167^{\star \star \star}$ \\
\hline & $(0.031)$ & $(0.031)$ & $(0.031)$ & $(0.031)$ & $(0.031)$ \\
\hline Personal economic stability & $\begin{array}{l}0.166^{\star * *} \\
(0.037)\end{array}$ & $\begin{array}{l}0.166^{\star * *} \\
(0.037)\end{array}$ & $\begin{array}{l}0.164^{* * *} \\
(0.037)\end{array}$ & $\begin{array}{l}0.166^{\star * \star} \\
(0.037)\end{array}$ & $\begin{array}{l}0.166^{\star * \star} \\
(0.037)\end{array}$ \\
\hline Employment expectations & $\begin{array}{l}0.505^{\star * *} \\
(0.029)\end{array}$ & $\begin{array}{l}0.505^{\star * *} \\
(0.029)\end{array}$ & $\begin{array}{l}0.505^{\star * *} \\
(0.029)\end{array}$ & $\begin{array}{l}0.505^{\star * *} \\
(0.029)\end{array}$ & $\begin{array}{l}0.505^{\star \star *} \\
(0.029)\end{array}$ \\
\hline \multirow[t]{2}{*}{ Safe neighborhood } & $0.173^{\star * *}$ & $0.173^{* * *}$ & $0.173^{\star * *}$ & $0.173^{\star * *}$ & $0.173^{* * *}$ \\
\hline & $(0.026)$ & $(0.026)$ & $(0.026)$ & $(0.026)$ & $(0.026)$ \\
\hline Self-placement in the society & $\begin{array}{l}0.166^{\star * *} \\
(0.033)\end{array}$ & $\begin{array}{l}0.165^{\star * *} \\
(0.033)\end{array}$ & $\begin{array}{l}0.166^{* * *} \\
(0.033)\end{array}$ & $\begin{array}{l}0.165^{\star * *} \\
(0.033)\end{array}$ & $\begin{array}{l}0.165^{\star * *} \\
(0.033)\end{array}$ \\
\hline \multirow[t]{2}{*}{ Trust in parties } & $2.942^{\star \star \star}$ & $2.942^{\star \star \star}$ & $2.942^{\star \star \star}$ & $2.942^{\star \star \star}$ & $2.942^{\star \star \star}$ \\
\hline & $(0.051)$ & $(0.051)$ & $(0.051)$ & $(0.051)$ & $(0.051)$ \\
\hline Years of democracy & $\begin{array}{l}0.020^{\star * *} \\
(0.006)\end{array}$ & & & $\begin{array}{l}0.006 \\
(0.008)\end{array}$ & \\
\hline Political instability & $\begin{array}{l}-0.728^{* *} \\
(0.251)\end{array}$ & & $\begin{array}{l}-0.495^{\star} \\
(0.242)\end{array}$ & & \\
\hline \multicolumn{6}{|l|}{$I V s$} \\
\hline \multicolumn{2}{|l|}{ COI Strictness Index } & $\begin{array}{l}-2.341^{* * *} \\
(0.699)\end{array}$ & $\begin{array}{l}-2.111^{* * *} \\
(0.501)\end{array}$ & $\begin{array}{l}-1.967^{\star * \star \star *} \\
(0.697)\end{array}$ & $\begin{array}{l}-2.329^{* * *} \\
(0.529)\end{array}$ \\
\hline \multicolumn{2}{|l|}{ COI Sanction Index } & $\begin{array}{c}0.309 \\
(0.516)\end{array}$ & & & \\
\hline \multicolumn{2}{|l|}{ COI Transparency Index } & $\begin{array}{l}-0.424 \\
(0.597)\end{array}$ & & & \\
\hline $\mathrm{BIC}$ & 16746.2 & 16756.0 & 16743.3 & 16746.5 & 16737.2 \\
\hline Chi2 & 3989.0 & 3989.4 & 3987.7 & 3987.7 & 3987.7 \\
\hline Log Likelihood & -8308.4 & -8308.4 & -8308.9 & -8308.9 & -8308.9 \\
\hline Individual observations & 20940 & 20940 & 20940 & 20940 & 20940 \\
\hline Countries & 25 & 25 & 25 & 25 & 25 \\
\hline
\end{tabular}

Log-odds; constants are not shown; standard errors in parentheses ${ }^{*} p<0.05,{ }^{* *} p<0.01$, ${ }^{* *} p<0.001$

Most importantly, we find a robust negative association regarding our COI Strictness index but not our other two indices, rather than finding similar relationships between trust and all three. This demonstrates the usefulness of our conceptual distinction between different types of $\mathrm{COI}$ constraints underpinning the separation of the indices. This is further 
substantiated as the nature of the constraints that our Strictness Index (composed of rule strictness and enforcement) reflects the theoretical mechanisms highlighted in the literature as rationalizing an expectation of a negative relationship between $\mathrm{COI}$ constraints and trust in the first place (see above): first, the tendency of tougher regulation to initially reveal more rule violations rather than preventing them, producing systematic evidence confirming citizens' suspicions about parliamentarians' unethical behaviour (e.g. Wilcox 2001; Rosenthal 2005); second, specifying the formerly blurred boundary between what is acceptable and what not or by problematizing behaviour that otherwise would have been accepted without question (e.g. Saint-Martin 2008).

Returning to our conceptualizations of our three elements of $\mathrm{COI}$ regimes, the $\mathrm{COI}$ Strictness Index captures clear-cut and constraining ethics rules which make formal rule violations more likely and thus might unintentionally raise citizens' expectations towards parliamentarians' behaviour. Similarly, strong enforcement structures as the second index component systematically increase chances of official detection. In contrast, transparency requirements might - when media attention is high - lead to occasional public outcries but third party control is not equivalent to a specialized enforcement structure engaged in ongoing systematic monitoring of rule compliance. This finding echoes theoretical works on transparency measures and their implications for public accountability as well as trust that are sceptical about these measures' effectiveness (Olsen 2013; O’Neil 2002). Furthermore, the detection of violations is likely to have more weight if confirmed as 'official misconduct' by a public authority (Allen 2011). Similarly, the relative severity and range of sanctions is unlikely to be as relevant to citizens, as compared to the official notification that MPs violate binding rules, as captured by our COI Strictness Index. These parallels between conceptual distinctions and the nature of our empirical findings stress the fruitfulness of conceptualizing and measuring different elements of $\mathrm{COI}$ regimes when engaging in cross-national analyses. 


\section{Conclusion and Future Research}

Over the last decade, the diversity of conflict of interest (COI) regulation applicable to national parliamentarians (as well as other public officials) has grown significantly in many democracies. Defined as the range of formal-legal restrictions to assure parliamentarians' impartial or unbiased decision-making when exercising their representative function (Nikolov 2013: 407), COI regulation embraces a wide range of diverse mechanisms which we capture across 11 substantive areas. These not only include (increasingly prominent) requirements for asset disclosure but also preventive rules able to impose constraints on parliamentarians' behaviour, both while being in office (e.g. restrictions on the receipts of gifts) and afterwards (e.g. cooling off requirements). This growing diversity creates a major challenge for crossnational research: the development of measures capturing the different elements of increasingly complex ethics regimes in an unbiased fashion, able to 'travel' across European democracies.

To tackle this challenge, this paper distinguished three conceptual dimensions of $\mathrm{COI}$ regimes applied to national parliamentarians as public representatives and developed measures to capture them empirically: COI strictness, sanctions and transparency. Based on a new dataset we showed that these indeed constitute empirically separate dimensions across the 26 democracies studied. To illustrate the usefulness of our analytical distinctions we then examined the relationship between the three $\mathrm{COI}$ indices and trust in national parliaments. Controlling for a range of individual-level and systemic factors theorized as relevant for trust in public institutions, our $\mathrm{COI}$ Strictness Index (combining rule strictness and enforcement structures) shows a significant and robust negative relationship with trust, while our COI Sanction and Transparency Indices do not, stressing the particular importance of COI Strictness, which mirrors theoretical arguments pointing to this element's centrality. This analysis on the relationship between $\mathrm{COI}$ regulation and trust highlights the fruitfulness 
of distinguishing these particular elements of parliamentary $\mathrm{COI}$ regimes in separate measures as compared to quantifying the intensity of regulation overall, a common strategy employed in analyses of the regulation of political parties (e.g. Whitley $2011 ; 2014$; but see Biezen 2012; Casal et al 2014). To pin down causal relationships between regulation and trust (or alternative attitudinal or behavioural variables), future research needs to assess the over-time evolution of ethics regimes across a wider range of democracies as a subset of parliamentary rules, whose comparative, longitudinal study has made significant advances in recent years (Sieberer et al 2011; 2016).

Importantly, while our framework captures the central components of ethics regimes regulating parliamentarians as representatives, it provides a sound foundation to engage in comparative analyses of regulation of their behaviour as party politicians and self-interested individuals as well. For instance, our conceptual distinctions can be used as a template to develop measures to study party finance regulation. While drawing on the party finance literature (e.g. Nassmacher 2003) to develop our framework, only few large-N studies have measured qualitatively different elements of party finance regimes separately (e.g. Casal et al 2014). Similarly, comparative studies of regulation trying to prevent the partisan use of institutional resources by MPs or of the enforcement of funding regulations more generally have received little attention so far (Bolleyer and Gauja 2015: 322; Clark 2015: 2). Finally, a narrower yet highly sensitive area of regulation is the one of MP expenses aiming at preventing parliamentarians to exploit institutional resources for their own financial gain (Allen and Birch 2015). While none of these areas of regulation targets MP legislative decision-making as $\mathrm{COI}$ regulation does, they often are equally contentious as also here those subject to the rules are usually involved in their making.

Acknowledgements: This paper forms part of a collaborative project on 'Conflict of Interest Regulation in Europe' jointly conducted with Fabrizio di Mascio and Alessandro Natalini. Many thanks go to them for their contributions to the project as well as to Nicolas Allen and 
the two WEP referees for their detailed and helpful feedback on the article. We also thank staff of the Centre of Comparative Politics, University of Cologne, of the School of Government and Public Policy, University of Strathclyde, and the participants in the panel 'Regulating Political Actors in Old and New Democracies: Parties, Politicians, Interest Groups' at the EPOP Conference in Cardiff, where we could present and discuss earlier versions of the article.

Funding: This research has received funding from the European Research Council under the European Union's Seventh Framework Programme (FP7/2007-13)/ERC grant agreement 335890 STATORG). This support is gratefully acknowledged. 


\section{Bibliography}

Aghion, Philippe, Yann Algan, Pierre Cahuc, Andrei Schlefer (2010). Regulation and Distrust, Quarterly Journal of Economics 125 (3): 1015-1049.

Allen, Nicholas (2008a). A New Ethical World of MPs? Journal of Legislative Studies 14(3): 297-314.

Allen, Nicholas (2008b). The Nolan Reforms and their Impact on the House of Commons. Unpublished PhD Thesis, University of Essex.

Allen, Nicholas (2011). Dishonourable Members? Exploring Patterns of Misconduct in the Contemporary House of Commons, British Politics 6 (2): 210-40.

Allen, Nicholas and Birch, Sarah. (2015). Ethics and Integrity in British Politics: How Citizens Judge their Politicians' Conduct and Why it Matters. Cambridge: Cambridge University Press.

Atkinson, Michael, M. and Maureen Mancuso (1991). Conflict of Interest in Britain and the United States: An Institutional Argument, Legislative Studies Quarterly 16 (4): 471-493.

Van Aaken, Anne and Stefan Voigt (2011). Do Individual Disclosure Rules for Parliamentarians Improve Government Effectiveness, Economic Governance 12: 301-24.

Biezen, Ingrid van and Kopecký, Petr (2008). The State and the Parties: Public Funding, Public Regulation and Rent-Seeking in Contemporary Democracies, Party Politics 13 (2): 235-254.

Biezen, Ingrid van (2012). Constitutionalizing Party Democracy: The Constitutive Codification of Political Parties in Post-war Europe, British Journal of Political Science 42 (1): 187-212.

Bolleyer, Nicole and Anika Gauja (2015). The Limits of Regulation: Indirect Party Access to State Resources in Australia and the UK, Governance 28 (3): 321-340.

Bovens, Mark (2010). Two Concepts of Accountability. Accountability as a Virtue and as a Mechanism, West European Politics 33 (5): 946-967.

Bovens, Mark, Goodin, Robert Edward and Schillemans, Thomas (Eds.) (2014). The Oxford Handbook of Public Accountability. Oxford: Oxford University Press.

Casal Bértoa, Fernando, Fransje Molenaar, Daniela R. Piccio, Ekaterina R. Rashkova (2014) The World Upside Down: Delegitimising Political Finance Regulation, International Political Science Review 35 (3): 355-375.

Catterberg, Gabriela and Moreno, Alejandro (2006). 'The Individual Bases of Political Trust: Trends in New and Established Democracies', International Journal of Public Opinion Research 18 (1): 31-48.

Clark, Alistair (2015). The Relationship between Political Parties and their Regulators, Party Politics, early view November 9.

Demmke, Christoph and Thomas Henökl (2007). Managing Conflicts of Interest- Ethic Rules and Standards in the Member States and the European Institutions, EIPASCOPE 2007/3, $35-41$. 
Demmke, C., M. Bovens, T. Henökl, K. van Lierop, T. Moilanen, G. Pikker and A. Salminen (2007). Regulating Conflicts of Interest for Holders of Public Office in the European Union, http://ec.europa.eu/dgs/policy advisers/publications/docs/hpo professional ethics en.pdf, accessed July 12015.

Djankov, Simeon, Rafael La Porta, Florencio Lopez-de-Silanes and Andrei Shleifer (2010). Disclosure of Politicians, American Economic Journal 2, 179-209.

Dunn, Kris (2012). Voice and trust in parliamentary representation, Electoral Studies 31 (2): 393-405.

Epstein, Leon E. (1989). Political Parties in the American Mold, Madison, WI: University of Wisconsin Press.

Gay, Oonagh (2006). Comparing Systems of Ethics Regulation, Public Ethics and Governance: Standards and Practices in Comparative Perspective 14: 93-107

Gilman, Stuart C., Joshua Joseph and Cheryl L. Raven (2002). Conflicts of Interest: Balancing Appearances, Intentions and Values, Ethics Resource Centre, December 31, 2002, http://www.ethics.org/?q=resource/conflicts-interest-balancing-appearancesintentions-and-values, accessed July 102015

Ginsberg, B., and Shefter, M. (1990). Politics by Other Means: The Declining Importance of Elections in America. New York: Basic Books.

Jepperson R.L. \& W. Meyer (1991) The Public Order and the Construction of Formal Organizations, in:W. W. Powell \& P.J DiMaggio(eds) The New Institutionalism in Organizational Analysis, Chicago: Chicago UP.

King, Simon (2003). Regulating the Behaviour of Ministers, Special Advisers and Civil Servants, London: Constitution Unit.

Loewenstein, George, Daylian M. Cain and Sunita Sah (2011). The Limits of Transparency: Pitfalls and Potential of Disclosing Conflicts of Interest, American Economic Review 101 (3): 423-428.

Mattarella, Bernardo Giorgio (2014). 'The Conflicts of Interest of Public Officials: Rules, Checks and Penalties' In: Corruption and Conflicts ofInterest, eds. Jean-Bernard Auby, Emmanuel Breen and Thomas Perroud, Cheltenham: Edward Elgar, pp. 30-38.

Messick, Richard E. (2014). 'Policy Considerations When Drafting Conflict of Interest Legislation'. In Jean-Bernard Auby, Emmanuel Breen, Thomas Perroud (Eds.): Corruption and conflicts of interest. A comparative law approach (Studies in comparative law and legal culture): 113-123.

NDI (1999) Legislative Ethics: A Comparative Analysis, Legislative Research Series, National Democratic Institute for International Affairs, Washington DC.

Nikolov, Nikolay (2013). Conflict of Interest in European Public Law, Journal of Financial Crime 20 (4): $406-421$

Nassmacher, Karl-Heinz (2003). 'Introduction: Political Parties, Funding and Democracy.' In Funding of Political Parties and Election Campaigns, eds. Reginald Austin and Maja 
Tjernström. Stockholm: International Institute for Democracy and Electoral Assistance, 1-19. Available online at: http://www.idea.int/publications/funding parties/funding of pp.pdf

OECD (2005). Managing Conflict of Interest in the Public Sector. A Toolkit, http://www.oecd.org/gov/ethics/49107986.pdf, accessed July 102015.

OECD (2008). Handbook on Constructing Composite Indicators. Methodology and User Guide. Paris.

O'Halloran, K. (2011). The Politics of Charity, London: Routledge.

Olsen, Johan P. (2013). The Institutional Basis of Democratic Accountability, West European Politics 36 (3): 447-473.

O'Neill, Onora (2002a) Reith Lectures: A Question of Trust, Lecture 1: Spreading Suspicion, http://www.bbc.co.uk/radio4/reith2002/, accessed November 292016.

O'Neill, Onora (2002b) Reith Lectures: A Question of Trust, Lecture 4: Transparency and Trust. http://www.bbc.co.uk/radio4/reith2002/lecture4.shtml, accessed November 292016.

Rose, Jonathan, Paul Heywood (2013). Political science approaches to integrity and corruption, Human Affairs 23 (2): 148-159.

Rose-Ackerman, Susan (2014). 'Corruption and Conflicts of Interest.' In: Corruption and Conflicts of Interest, eds. Jean-Bernard Auby, Emmanuel Breen and Thomas Perroud, Cheltenham: Edward Elgar, 3-14.

Rosenson, Beth Ann (2009). The Effect of Reform Measures on Perceptions of Corruption, Election Law Journal 8(1), 31-46.

Rosenthal, Alan (2005). The Effects of Legislative Ethics Law: An Institutional Perspective, Public Ethics and Governance: Standards and Practices in Comparative Perspective 14: 155-77.

Sah, Sunita, George Loewenstein, G., and Daylian M. Cain (2013). The Burden of Disclosure: Increased Compliance with Distrusted Advice, Journal of Personality and Social Psychology 104 (2): 289-304.

Saint-Martin, Denis (2008). The Watergate Effect: Or, Why Is the Ethics Bar Constantly Rising? In Christine Trost, Alison L. Gash(eds) Conflict of Interest and Public Life: CrossNational Perspectives, Cambridge: Cambridge UP, pp. 35-55.

Sieberer, Ulrich, Wolfgang C. Müller, and Maiko I. Heller (2011) Reforming the Rules of the Parliamentary Game: Measuring and Explaining Changes in Parliamentary Rules in Austria, Germany, and Switzerland, 1945-2010, West European Politics 34 (5): 948-75.

Sieberer, Ulrich, Peter Meißner, Peter, Julia F. Keh, Wolfgang C. Müller (2016). Parliamentary Rule Changes in Europe: A Research Program, Legislative Studies Quarterly 41 (1): 63-88. 
Torcal, Mariano (2014). The Decline of Political Trust in Spain and Portugal: Economic Performance or Political Responsiveness? In American Behavioral Scientist 58 (12), 15421567.

Van der Meer, T. (2010). In What We Trust? A multi-level study into trust in parliament as an evaluation of state characteristics. In International Review of Administrative Sciences 76 (3), 517-536.

Van Deth, Jan (1998). Comparative Politics: The Problem of Equivalence, London: Routledge.

Whiteley, Paul (2011). Is the Party Over? The Decline of Party Activism and Membership across the Democratic World, Party Politics 17 (1): 21-44.

Whiteley, Paul (2014).. Does regulation make political parties more popular? A multi-level analysis of party support in Europe, International Political Science Review 35 (3): 376-399.

Williams, Robert (2006). The Ethics Eruption: Sources and Catalysts, Research in Public Policy Analysis and Management 14: 29-42.

Zmerli, Sonja and Ken Newton (2011). Winners, Losers and Three Types of Trust. In: Sonja Zmerli und Marc Hooghe (Hg.): Political trust. Why context matters. Colchester, UK: ECPR Press (Studies in European political science): 67-94. 